\title{
Hurricane and waste collection simulations on QGIS for improving post-hurricane waste collection
}

\author{
Quy Thy Truong a ${ }^{\text {, Anne Ruas }}{ }^{\mathrm{b},{ }^{*}}$, Serge Lhomme ${ }^{\mathrm{c}}$ \\ ${ }^{a}$ Université Gustave Eiffel, COSYS Laboratory, truong.quythy@gmail.com \\ ${ }^{b}$ Université Gustave Eiffel, COSYS Laboratory, anne.ruas@univ-eiffel.fr \\ c Université Paris-Est Créteil, Lab'Urba, serge.lhomme@u-pec.fr \\ * Corresponding author
}

Keywords: Early Warning and Crisis Management, Hurricane, Waste management; Q-GIS

\begin{abstract}
:
In the past decades, catastrophic natural disasters such as storms and hurricanes have impacted millions of people around the world: around 33 million of people are affected per year between 2007 and 2016 (Bellow and Wallemacq, 2018). For instance, hurricane Katrina (USA, 2015) caused catastrophic damage from central Florida to Eastern Texas, at least 1836 people died and total property damage was estimated at 125 billion dollars. Furthermore, climate change is likely to increase frequency of most intense categories of hurricanes and is expected to increase sea levels, leading to more destructive storm surges when hurricanes occur (IPCC, 2013). Hurricanes generate large amounts of waste directly related to the induced impacts (Brown et al., 2011). The speed of waste collection and sorting is essential because the waste not only block or slow down human activity but it also generates pollution. The management of this waste is therefore a major issue in post-hurricane crisis management. Hurricane Irma, which hit the Caribbean in early September 2017, in particular the islands of Saint-Martin and Saint-Barthelemy, is a striking example of this problem. In this paper we present an information system to improve the collection of post-hurricane waste in the French West Indies.
\end{abstract}

The first step of our research consisted of analyzing the waste collection process during Hurricane Irma on the island of Saint-Martin. The information collected during several field missions (Beraud et al., 2019) as well as damage data identified from satellite images made it possible to estimate the volume of waste and to understand the collection process (Ruas et al., 2021). In this paper we present the last part of our research which consists in the development of a prototype allowing to simulate the collection of waste from buildings damaged during the passage of a hurricane. In the following we focus on building waste which include construction and demolition debris as well as household goods wastes (furniture, clothes, and wastes of electrical and electronic equipment) as they constitute the largest waste volume.

The process was first designed from the data available after the passage of Irma on the island of Saint-Martin. It was then enriched and generalized to be applied to another territory and from a simulated hurricane. The purpose of this tool is to allow communities and stakeholders to test their equipment and resources for waste collection and to imagine other solutions to reduce delays and improve sorting and recycling. The simulation tool will be presented in details in fall 2021 in Guadeloupe to stakeholders (emergency planners or waste managers) to collect opinions and improve functionalities.

The process is made up of three steps: the simulation of buildings damage, the calculation of the location of drop-off areas near the damaged buildings and finally the calculation of waste collection from the drop-off areas to waste treatment or storage plants. This process is implemented as a free and open source QGIS plugin (figure 1).

\section{The simulation of damaged building}

Actually, after the passage of hurricanes, remote sensing methods are increasingly used to assess the degree of damage to buildings. This is the case for the passage of Hurricane Irma on the island of Saint Martin where two companies produced two vector databases to identify damaged buildings classified by categories of damage according to the EMS98 standard. These data give proportion of damaged buildings per category. A post analysis showed that for the island of Saint Martin the damage was strongly related to the building position (Ruas et al, 2021). We use by default this distribution of damaged buildings for other territories but we can also exaggerate or attenuate the proportion of damage buildings. When percentages of damaged building are set, the algorithm chooses buildings randomly until the desired proportion per category is reached. But the case of Saint Martin is special because the island is very small. So it is possible to add a hazard partition map to distinguish the proportion of damaged buildings per area. For example one can use a marine risk submersion map to distinguish the proportion of damaged buildings according to this criteria. Once 
the damage buildings are chosen, the volume of waste is computed according to a waste volume function related to the building size and the damage level. The function was deduced from data collected on Saint Martin.

\section{The location of deposit area}

After hurricane, dwellers carry waste and debris either in front of their house or on close dedicated ephemeral areas, called the deposit areas. The waste located on these deposit areas will then be transported to temporary storage areas before being transported to their final destination for recycling or storage. But the first location of these deposit areas should be defined. We proposed 4 ways to compute the position of the deposit areas location: in front of each house, at the closest intersection, at the closest large intersection, or on a road network with possible clustering at a distance depending on the volume to displace which seems to be the most realistic solution.

\section{The simulation of the collection}

The simulation algorithm for waste collection is based on an algorithm of the shortest path on the road network between origins (the deposit areas) and destinations (the temporal storage areas). It simulates the movement of trucks which collect the waste and bring it to the nearest destination within the limit of the volume of transportable waste. The complexity of the process is therefore not in the algorithm itself but in the parameters making it possible to best take into account all the collection configurations. The proposed simulation tool enables to take into account the collection basins, the number of truck per basin and their volume, the loading and unloading times. It also allows to integrate the types of waste and to differentiate the destinations according to the types of waste they accept. Therefore, the simulations enable to study multiple sorting strategies (figure 1).



Figure 1. DéPOs interface allowing the configuration of waste sorting for collection

\section{Acknowledgements}

The authors would like to thank the National Research Agency which supports the Post Ouragan Waste research project (ANR-18-OURA-0003) and all the partners of the ANR DéPOs: Gustave Eiffel University, Le Mans University, Avignon University, Robin des Bois Association and University of Mons (associate international partner).

\section{References}

Below, R., Wallemacq, P., 2018, Annual Disaster Statistical Review 2017, CRED, Centre for Research on the Epidemiology of Disasters.

Beraud, H., Nithart, C., Durand, M., 2019, Le difficile suivi des déchets post-catastrophe : le cas de l'Ouragan Irma à Saint-Martin, Risques urbains, ISTE Ltd., p24

Brown, C., Milke, M., Seville, E. ,2011, Disaster waste management: A review article, Waste Management, 31(6), pp. 1085-1098.

Intergovernmental Panel on Climate Change, 2013. Climate Change 2013: The Physical Science Basis.

Ruas A., Lhomme S., Lamour M., 2021, Localisation et estimation des volumes de déchets suite à l'ouragan Irma à Saint-Martin, Risques urbains, N²1, Vol 3, 10.21494/ISTE.OP.2021.0634 ISSN : 2516-1857. 